\title{
RETRATOS DA VIVÊNCIA AMAZÔNICA: CONTRIBUIÇÃO DA PRÁTICA EDUCOMUNICATIVA NO APERFEIÇOAMENTO DA REPRESENTAÇÃO DA REALIDADE MARAJOARA ${ }^{1}$
}

\author{
Hericley Serejo Santos ${ }^{2}$ \\ Instituto Federal do Pará (IFPA) \\ hericleyrp@gmail.com \\ Elias Santos Serejo ${ }^{3}$ \\ Universidade Federal do Pará (UFPA) \\ eliassantos1001@gmail.com \\ Luã Caldas de Oliveira ${ }^{4}$ \\ Universidade Federal do Pará (UFPA) \\ oliveiraxd2@gmail.com
}

\begin{abstract}
Resumo
A educação é um dos caminhos para diminuir a desigualdade no acesso às tecnologias de informação e comunicação. Na interface entre Educação e Comunicação, a prática educomunicativa apresenta-se, então, como alternativa para desenvolver linguagens que os dispositivos digitais promovem, como a fotografia. Neste trabalho, buscamos compreender como essa abordagem contribuiu para melhorar a captura de imagens por discentes do Instituto Federal do Pará, Campus Breves, localizado no Marajó, e transformar o olhar crítico para o espaço em que estão inseridos, a partir da realização de uma oficina de fotografia. Para isso, analisamos os dados coletados por meio da aplicação de questionário. Percebemos que a familiaridade dos jovens em utilizam recursos tecnológicos não garante o domínio teórico sobre o funcionamento e potencialidade disponibilizados por eles, demonstrando que a Educomunicação pode contribuir para que essa lacuna seja preenchida, possibilitando o alcance de melhores resultados na busca de uma educação cidadã e emancipatória.
\end{abstract}

Palavras-chave: Educomunicação. Tecnologia. Fotografia. Amazônia.

\section{PORTRAITS OF THE AMAZONIAN EXPERIENCE: CONTRIBUTION OF THE EDUCOMMUNICATIVE PRACTICE IN THE IMPROVEMENT OF THE REPRESENTATION OF THE MARAJOARA REALITY}

\begin{abstract}
Education is one of the ways to reduce inequality in access to information and communication technologies. At the interface between Education and Communication, educommunicative practice is presented as an alternative to develop languages that digital devices promote, such as photography. In this paper, we seek to understand how this approach contributed to improve the capture of images by students of the Federal Institute of Pará, Campus Breves, located in Marajó, and transform the critical look at the space in which they are inserted, by conducting a workshop of photography. For this, we analyzed the data collected by applying a questionnaire. We realize that the familiarity of young people in using technological resources does not guarantee the theoretical mastery over the functioning and potentiality provided by them, demonstrating that Educommunication can contribute to fill this gap, enabling the achievement of better results in the pursuit of a citizen education. emancipatory.
\end{abstract}

Keywords: Educommunication. Tecnology. Photography. Amazonia.

\footnotetext{
${ }^{1}$ Este artigo é uma versão aprimorada do trabalho de mesmo título apresentado no II Congresso Internacional de Comunicação e Educação e VIII Encontro Brasileiro de Educomunicação, no Grupo Temático Trajetória - Construindo caminhos a partir da prática educomunicativa, realizado de 12 a 14 de novembro de 2018 na Universidade de São Paulo (NCE/USP).

${ }^{2}$ Relações Públicas do Instituto Federal do Pará, Campus Breves-PA. Mestrando em Educação Profissional e Tecnológica (IFPA). MBA em Marketing, Propaganda e Comunicação Integrada. Especialização em Gerenciamento de Projetos - Práticas PMI. Membro da ABPEducom.

${ }^{3}$ Mestre pelo Programa de Pós-Graduação em Comunicação, Linguagens e Cultura (Unama). Doutorando pelo Programa de Pós-Graduação Comunicação, Cultura e Amazônia (PPGCOM/UFPA). Bolsista CAPES. E-mail: eliassantos1001@gmail.com ${ }^{4}$ Professor do Ensino Básico, Técnico e Tecnológico do Instituto Federal do Pará, Campus Breves-PA. Doutor em Ciência e Tecnologia de Alimentos (PPGCTA-UFPA). Mestre em Ciência e Tecnologia de Alimentos (PPGCTA-UFPA). Especialista em Docência do Ensino Básico, Técnico e Tecnológico (IFPA). Tecnólogo em Alimentos (CCNT-UEPA).
} 


\section{INTRODUÇÃO}

O desenvolvimento e os avanços das tecnologias de informação e comunicação exercem diferentes impactos na sociedade. O processo comunicativo estabelecido entre os sujeitos passou a contar com a mediação de elementos que provocou uma nova dinâmica na percepção das dimensões do tempo e do espaço, não as limitando à transposição dos contextos geográficos e nem se esgotando na instrumentalização dos aparatos tecnológicos. O surgimento do correio eletrônico ou das redes sociais online, por exemplo, promoveram mudanças que vão além do envio de mensagens e da rápida propagação de informações, alterando a interação em diferentes ambientes de socialização e se constituindo como parte de fatores externas que exercem influências sobre o comportamento humano. Dos meios de produção às relações econômicas e sociais, as transformações tecnológicas influenciam diretamente na forma como a sociedade vive e estrutura sua história. $\mathrm{O}$ acesso a esses recursos permite aos indivíduos experiências que alteram hábitos e, consequentemente, a maneira como se informam, adquirem conhecimento e compartilham o saber (CORREA, 2017).

Entretanto, diferente do apelo promovido pelo consumo mercadológico, que busca evidenciar uma homogeneidade no acesso às tecnologias, o uso e apropriação dos dispositivos digitais que viabilizam a rapidez do fluxo de informações não está ao alcance de todos de forma equitativa, o que é mais perceptível em regiões com maior incidência de vulnerabilidade social, como o arquipélago do Marajó, no Pará. A mesorregião, considerada o maior arquipélago fluviomarítima do mundo, expõe claramente os contrastes entre a exuberância natural e as problemáticas de caráter social, econômico, político, entre outras. E, se por um lado a tecnologia torna-se mais presente no cotidiano dessas populações, por outro, ainda há pouca representação e exposição de sua realidade, cultura e saberes a partir dos conteúdos veiculados em espaços acadêmicos e midiáticos (PACHECO, 2012).

A complexidade em solucionar a desigualdade no acesso e na representação nesses espaços permeados pelas tecnologias não nos permite eleger pontualmente propostas de fácil abordagem, mas é possível apontar alguns prováveis caminhos, entre os quais destacamos a educação, que conta entre os seus atuais desafios a compreensão e o domínio dessa dimensão onde ocorrem as mútuas trocas entre os indivíduos. Há contínuos esforços para se desenvolver métodos de ensino-aprendizagem e práticas pedagógicas condizentes às atuais necessidades da formação humana (SHULMAN, 2014). Ao mesmo tempo, é primordial oferecer um ensino que tenha em vista a formação integral do cidadão, que dê condições para que reflita sobre aquilo 


\section{INOVAÇÃO}

que lhe é imposto pelo constructo social e decida o melhor posicionamento a assumir. Desta forma, ele pode desenvolver autonomia para desempenhar um papel de agente transformador da própria realidade (ARAÚJO; FRIGOTTO, 2015).

Diante desse contexto, a Educomunicação apresenta-se como uma abordagem conceitual que tem entre as formas de materialização a "mediação tecnológica na educação: compreendendo o uso das tecnologias da informação nos processos educativos" (CORREA, 2017, p.36). Da educação infantil à formação continuada, as práticas educomunicativas envolvem diferentes formatos de intervenção e de linguagens que perpassam as mídias alternativas $^{5}$. A produção de textos informativos ou jornalísticos e a captura e edição audiovisual, sonora e fotográfica são algumas das possibilidades que se apresentam no processo de apropriação das linguagens midiáticas para potencializar as capacidades comunicativas de estudantes em diferentes níveis de ensino (ALMEIDA, 2016).

$\mathrm{O}$ avanço tecnológico em equipamentos destinados à produção de conteúdo, como computadores, máquinas fotográficas, filmadoras e celulares, antes reservados a pequenos grupos detentores de poder aquisitivo compatível, permitiu expandir o acesso a esses recursos para camadas sociais menos privilegiadas, um movimento que sofre influência direta da necessidade de aumento do consumo. Entre as linguagens comunicativas que tais dispositivos promovem, destacamos a fotografia, uma das materialidades da comunicação visual que recebe destaque na interação entre os sujeitos em redes sociais online, e, por conseguinte, um dos elementos objeto de estudo e de ensino em diversas práticas educomunicativas (VIANA; MELLO, 2013). A realização de oficinas de fotografia, associadas a objetivos mais amplos, geralmente relacionados à produção artística ou para a disseminação de informações, é cada vez mais presente em projetos educacionais promovidos a partir de iniciativas públicas ou privadas, com o intuito de proporcionar um melhor letramento digital nas escolas (VIANA; MELLO, 2013).

Por isso, neste trabalho, contamos como se deu o processo de construção e desenvolvimento de uma oficina de fotografia realizada no âmbito do projeto de extensão "O aprimoramento da fotografia como recurso de descrição da realidade marajoara", no Instituto Federal do Pará, Campus Breves, localizado no Marajó. A descrição do processo culmina em uma análise acerca das transformações ocorridas na forma como os discentes elaboram

\footnotetext{
${ }^{5}$ As mídias alternativas, ao contrário dos meios de comunicação de massa, expressam uma comunicação mais popular por meio da apropriação de linguagens, como rádios comunitárias, jornais de bairro e páginas na internet, e receberam significativa relevância nos anos 70 e 80 no Brasil a partir da iniciativa de movimentos sociais (PERUZZO, 2007).
} 


\section{INOVAÇÃO}

narrativas visuais sobre seus modos de viver. Especificamente, buscamos compreender como a prática educomunicativa contribuiu para melhorar a captura de imagens pelos discentes e transformar o olhar crítico para o espaço em que estão inseridos.

Participaram da atividade 20 discentes do curso Técnico em Agropecuária subsequente ao ensino médio. Para contextualizar a análise e compreender melhor os interlocutores da intervenção educativa, elaboramos um breve perfil dos estudantes que buscou compreender: (a) os fatores que contribuíam direta e indiretamente para as dificuldades em manusear os próprios celulares; (b) como receberam as instruções técnicas para utilizar os equipamentos para produzir as imagens; e a (c) percepção sobre a importância de terem contato com um conhecimento normalmente não abordado no currículo do curso que realizam.

O trabalho surge de inquietações originadas de observação de campo. O referido curso, do qual participam os estudantes interlocutores dessa pesquisa, funciona em regime de pedagogia da alternância ${ }^{6}$. Ao retornar para escola, depois do período que atuam nas próprias comunidades onde vivem, os alunos precisam elaborar relatórios para justificar suas atividades e contar suas vivências. Esses relatórios demandam a apresentação de fotografias, que, além de contribuir com a avaliação do professor, demonstram como estão pondo em prática as expertises aprendidas em sala de aula.

Nesse contexto, observamos que os referidos estudantes apresentavam dificuldades em capturar, por meio das fotografias, a realidade encontrada em seus territórios de atuação e as intervenções práticas realizadas. O material apresentado dificultava a tradução das vivências e não dava conta das nuances e detalhes fundamentais para compreensão da relação homem versus natureza, essencial ao desenvolvimento do conhecimento humano. Mau enquadramento, problemas com fonte de luz, primeiro plano desfocado, entre outros quesitos técnicos depreciavam a qualidade das imagens. A oficina foi realizada como uma tentativa de preencher uma lacuna no conhecimento sobre noções básicas de fotografia.

\section{A EDUCOMUNICAÇÃO E OS AVANÇOS DAS TECNOLOGIAS DE INFORMAÇÃO E COMUNICAÇÃO}

\footnotetext{
${ }^{6}$ A alternância pedagógica é uma concepção de educação que alterna as atividades pedagógicas realizadas na escola com atividades planejadas para serem executadas nas comunidades rurais, onde o processo educativo tem como princípio a pesquisa da realidade dos estudantes (MARINHO, 2015 apud INSTITUTO FEDERAL DO PARÁ, 2016).
} 
A popularização de equipamentos tecnológicos, a exemplo dos celulares, permitiu a inserção dos indivíduos em um ambiente virtual que os leva continuamente a fundi-lo ou sobrepô-lo ao real. Para Soares (2000, p. 14), isso ocorre devido às tecnologias proporcionarem "a concretização dos desejos e aspirações humanas em maneiras analógicas, através dos simulacros presentes no cotidiano da produção simbólica do sistema de comunicação". Tal fenômeno traz vantagens e desvantagens, uma vez que as tecnologias exercem influência direta sobre o processo decisório do indivíduo, bem como sobre suas interações sociais e o modo de vida (SACCOL, REINHARD, 2005, apud OLIVEIRA, UBAL e CORSO, 2014).

Até os anos 2000, o acesso às tecnologias de informação e comunicação era restrito a um grupo de cidadãos de significativo poder aquisitivo. Nos anos seguintes o Brasil vivenciou a massificação das ferramentas, sobretudo as digitais, tendo como um dos propulsores a ascensão econômica proporcionada pelas políticas públicas dos governos vigentes.

O uso de smartphones (celulares inteligentes, em tradução livre) é um dos exemplos da popularização das tecnologias da informação e comunicação e já alcança números superlativos no Brasil atual: existe mais de um aparelho ativo por habitante no Brasil, somando 220 milhões de dispositivos ${ }^{7}$. Entre as diversas funções que pode oferecer aos usuários, o acesso à internet é um dos destaques. Ainda que seja vislumbrado um futuro de cobertura territorial da internet banda larga ampla e irrestrita, o mapa de acesso à internet ainda expõe a desigualdade social que exclui parcela significativa da população.

Pesquisa do Comitê Gestor da Internet no Brasil (CGI.br) ${ }^{8}$, apontou que das 120,7 milhões de pessoas que acessaram a internet no país nos meses de abril, maio e junho de 2018, cerca de $49 \%$ utilizaram exclusivamente o celular. O levantamento aponta, ainda, que a classe A está $99 \%$ conectada, enquanto a classe D e E apenas $30 \%$, dos quais $80 \%$ é feito via dispositivo móvel.

Quanto maior o envolvimento com as diversas possibilidades que esses recursos proporcionam aos usuários, maior a familiaridade e a dependência criada pela demanda social e mercadológica. Essa relação do indivíduo com a tecnologia é motivada, conforme expressa Ribeiro et al. (2009, apud OLIVEIRA, UBAL e CORSO, 2014), pela maneira diferente com que o usuário vivencia as experiências oriundas de situações sociais cotidianas.

\footnotetext{
${ }^{7}$ Estadão. Brasil já tem mais de um smartphone ativo por habitante, diz estudo da FGV. Disponível em: https://link.estadao.com.br/noticias/geral,brasil-ja-tem-mais-de-um-smartphone-ativo-por-habitante-dizestudo-da-fgv,70002275238. Acesso em: 28 ago. 2018.

${ }^{8}$ Folha de São Paulo. Celular é mais utilizado do que computador para acessar internet no Brasil. Disponível em: https://www1.folha.uol.com.br/tec/2018/07/celular-e-mais-utilizado-do-que-computador-para-acessarinternet-no-brasil.shtml. Acesso em 28 ago. 2018.
} 
A facilidade no acesso às tecnologias da informação e comunicação requer aos educadores uma permanente atualização sobre as metodologias, técnicas e práticas de ensino, de forma a utilizar tais tecnologias a favor da autonomia e consciência crítica dos discentes (CORREA, 2017). Não se pode esperar que indivíduos que interagem com equipamentos tecnológicos, mesmo antes de alfabetizados, sejam capazes de desenvolver, de forma independente, uma compreensão sobre o uso desses recursos para resolver questões práticas ligadas à sua própria formação humana. Porém, é insuficiente apenas adquirir recursos tecnológicos e utilizá-los para o repasse de conhecimento, conforme discute Paulo Freire (2005, apud CORREA, 2017). Faz-se necessário viabilizar práticas dialógicas e críticas que superem o distanciamento existente entre "quem domina e repassa o conteúdo" e "quem recebe de maneira pacífica" (CORREA, 2017, p. 23).

Para Paulo Freire (1977, p.69 apud CORREA, 2017, 25), “a educação é comunicação, é diálogo, na medida em que não é a transferência do saber, mas um encontro de sujeitos interlocutores que buscam a significação dos significados”. Por isso, é impossível dissociar a educação da comunicação, uma vez que ambas as áreas de conhecimento estão relacionadas e proporcionam relações dialógicas entre si (CORREA, 2017). É dessa interface que surge a Educomunicação. De acordo com Soares (2014, p.23-24, apud CORREA, 2017, p. 24), a Educomunicação é um campo epistemológico que busca

transformações sociais que priorizem, desde o processo de alfabetização, o exercício da expressão, tornando tal prática solidária fator de aprendizagem que amplie o número de sujeitos sociais e políticos preocupados com o reconhecimento prático, no cotidiano da vida social, do direito universal à expressão e à comunicação.

Para Soares (2000), o campo de inter-relação entre Comunicação e Educação é uma resposta às transformações provocadas pelos avanços da tecnologia e o seu uso nos processos de ensino-aprendizagem, que passaram a exigir uma "profunda revisão do sentido da ação comunicativa presente no ato educativo - quer o presencial, quer o à distância" (SOARES, 2000, p. 13). A interação entre os dois campos não está restrita ao espaço institucionalizado da educação formal, mas estende-se a canais, difusos e descentralizados, que fazem o saber circular fora da escola, "um dos desafios mais fortes que o mundo da comunicação apresenta ao sistema educacional" (BARBERO, 2011, p. 126 apud CORREA, 2017, p. 27).

Ao citar Mário Kaplún, Soares (2000, p. 20) pontua que a relação entre Comunicação e Educação não trata de se usar a primeira como um instrumento para a segunda, mas converter essa interação em um "eixo vertebrador dos processos educativos", educando pela comunicação e não para ela e concedendo "métodos e procedimentos para formar a competência 
יגקי

\section{INOVAÇÃO}

comunicativa do educando", de forma a direcioná-lo para uma "educação cidadã emancipatória".

A Educomunicação é, então, compreendida como o conjunto de ações planejadas e implementadas para a criação e o desenvolvimento de ecossistemas comunicativos em espaços educativos, que prezam a participação ativa dos interlocutores e proporciona condições para reverberem as vozes que ecoam neles enquanto sujeitos sociais (SOARES, 2011). Diferente de abordagens meramente instrumentais de inserção das tecnologias e seus recursos no processo de ensino e aprendizagem, a proposta da Educomunicação é romper os limites do ambiente escolar para alcançar outros âmbitos da vida por considerar as influências e os impactos que a imersão tecnológica e midiática exerce sobre a sociedade (OROZCO, 2014).

A partir de projetos educomunicacionais, as práticas educomunicativas são desenvolvidas sob critérios essenciais que prezam a participação ativa de todos os sujeitos envolvidos; a finalidade educativa, com a clareza da metodologia e dos objetivos entre os participantes; a continuidade no processo de desenvolvimento da prática, que diz respeito ao amadurecimento, acompanhamento, reflexão crítica e a capacidade de enfrentar imprevistos; e a repercussão social para a comunidade dos resultados obtidos, a ser efetivada pela disponibilização do curso sobre a prática que será desenvolvida (KOFFERMANN, 2018). Outro princípio que norteia esse tipo de prática educativa é a compreensão da importância das mediações culturais e múltiplas no jogo de ressignificações realizado pelos sujeitos diante das mensagens veiculadas pelas mídias (MARTÍN-BARBERO, 1997; OROZCO GÓMES, 2014), onde estes ultrapassam o papel de receptores e adotam uma postura mais ativa tanto no processo de leitura e compreensão dos conteúdos, quanto na iniciativa de produzi-los e propaga-los nos ambientes virtuais de interação. Essas mediações dizem respeito ao espaço simbólico que existe entre o sujeito e a mensagem, composto pelo conjunto de "crenças, costumes, sonhos e medos, tudo o que configura a cultura cotidiana" (MARTÍN-BARBERO; BARCELOS, 2000, p. 154) e também por outras características que o compõe, advindas "da linguagem, do contexto, da classe social, da raça, da idade, da conformação individual" (OROZCO, 2001 apud OROZCO, 2014, p. 63-64).

\section{FOTOGRAFIA: UM CAMPO DA EXPRESSÃO HUMANA}

Etimologicamente, a palavra fotografia tem origem em expressões que simbolizam “escrever com a luz”. A escrita pressupõe autoria. Logo, fotografar é um exercício de tradução de uma dada realidade, muito mais do que um simples ato de clicar um aparelho. Com o advento 
dos smartphones e da ampla participação da população em redes sociais online, a fotografia se democratizou e tornou-se um dos principais meios de expressão de sentimentos, vide os inúmeros memes que surgem a partir de um único registro fotográfico, para citarmos apenas um exemplo entre vários. Com pequenos aparelhos é possível captar momentos e eternizá-los.

A fotografia está presente na vida da juventude. Em casa, na escola e na rua, as selfies são a sensação da segunda metade da década de 2010. Para proporcionar outras possibilidades de se relacionar com esse ato tão comum na rotina contemporânea é fundamental desenvolver estratégias de resgate da sensibilidade do olhar para elementos da vida cotidiana já tão vulgarizados. É com essa proposta que nasce este artigo. Contudo, para evidenciarmos o papel do campo fotográfico nas escolhas metodológicas feitas, tanto neste estudo quanto na própria oficina, faz-se necessário elencar nesse tópico algumas perspectivas que nortearam o trabalho.

Segundo Mauad (1996), existem diferentes abordagens fotográficas ao longo da história, o que faz com que o próprio campo de estudos da fotografia possua diferentes características, sobretudo no ocidente. Para a autora, a perspectiva que considerava a imagem como realidade "pura e simples já foi criticada por diferentes campos do conhecimento, desde a teoria da percepção até a semiologia pós-estruturalista” (MAUAD, 1996, p. 03).

Novas contribuições ao campo trouxeram outras nuances, a partir da qual revelaram-se abordagens que são caras a este estudo. Para efeitos do campo da educação, consideramos que a imagem fotográfica possui forte apelo interpretativo, cujo tempo e espaço são datados, logo historicamente determinados (MAUAD, 1996).

Como propõe Mauad (1996, p. 04), é fundamental "compreender que entre o objeto e a sua representação fotográfica interpõe-se uma série de ações convencionalizadas, tanto cultural como historicamente". A fotografia, e por conseguinte o momento por ela capturado, é resultado de um processo de escolhas, que dizem respeito tanto aos aspectos técnicos do equipamento quanto aos elementos sociais, culturais - e por que não ambientais? - aos quais os indivíduos produtores das imagens estão sujeitos.

Em um contexto de isolamento sócio-político aos quais os estudantes do IFPA Campus Breves estão submetidos, a constante empreitada do capital e os modelos de ideal de vida por ele vendidos e o fato desses sujeitos estarem dispersos em uma projeção imagética que não insere seus próprios estilos de vida como uma possibilidade de realização, é compreensível a ausência de sensibilidade para as próprias riquezas.

Talvez seja no contexto desenhado acima que tenham surgidas as dificuldades relatadas na abertura deste trabalho. Afinal, a "fotografia é interpretada como resultado de um trabalho social de produção de sentido, pautado sobre códigos convencionalizados culturalmente" 


\section{INOVAÇÃo}

(MAUAD, 1996, p. 07). Trata-se da decodificação de uma mensagem que encontra em cada tempo em que é recebida uma nova possibilidade interpretativa. "Estabelecem-se, assim, não apenas uma relação sintagmática, à medida em que veicula um significado organizado, segundo as regras da produção de sentido nas linguagens não-verbais, mas também uma relação paradigmática" (MAUAD, 1996, p. 07).

A fotografia é, portanto, um campo da expressão humana, que necessita de um recorte, ou seja, uma seleção de fatores construída intencionalmente para ser desenvolvida. Assim, é possível resgatar em estudantes inseridos em contexto de campos e florestas - por meio de práticas pedagógicas educomunicativas - a sensibilidade para capturarem a riqueza imagética de suas próprias localidades e dos trabalhos que desenvolvem no tempo-comunidade. No entanto, vale ressaltarmos que, na abordagem educomunicativa, diante da tarefa de capturar em imagem a realidade em que vivem, sem ignorar a relevância da estética e de tantos outros elementos que compõem a produção fotográfica, a técnica é sobreposta pelas mediações que favorecem a ampliação dos diálogos sociais e educativos (SOARES, 2011), dando condições para uma formação mais condizente às necessidades demandadas por sua realidade.

\section{IFPA CAMPUS BREVES: A EDUCAÇÃO PROFISSIONAL E TECNOLÓGICA NA AMAZÔNIA MARAJOARA}

A Educação Profissional e Tecnológica conta em seu percurso histórico com disputas entre projetos societários que se dividem entre promover uma educação voltada à formação humana e cidadã e restringir o processo educativo ao atendimento único e exclusivo das necessidades do capitalismo. Essa modalidade de ensino surge para desenvolver mão de obra minimamente qualificada a partir do ensino voltado àqueles que viviam à margem da sociedade (TAVARES, 2012).

Com o início da industrialização no Brasil, no final do século XIX, a Educação Profissional passa a receber mais atenção, mas somente na década de 1990 foi regulamentada, pouco tempo antes dos Institutos Federais passarem por reformulações, em 2000, que os levaram à uma concepção de formação humana integral, baseada na investigação científica e inovação tecnológica. Dez anos após, os Institutos Federais apresentavam um crescimento de 150\%, em relação ao período de 1909 a 2002, contabilizando 366 unidades em todo o país (TAVARES, 2012). É nesse contexto de expansão que o Campus Breves do Instituto Federal do Pará é estruturado. 
Localizado na mesorregião do Marajó, em especial em sua área de abrangência (Afuá, Anajás, Bagre, Breves, Chaves, Curralinho, Gurupá, Melgaço e Portel), o IFPA Campus Breves busca promover a educação profissional e tecnológica através do ensino, pesquisa e extensão, articulando os saberes e a diversidade sociocultural para formação de cidadãos comprometidos com o desenvolvimento sustentável marajoara. Atualmente, o Campus conta com cerca de 780 matrículas ativas de alunos distribuídos em 14 turmas, apresentando uma verticalização do ensino que parte de cursos de Formação Inicial Continuada (FIC), destinados a quem tem o Ensino Fundamental incompleto, até a oferta de cursos técnicos integrados ou subsequentes ao Ensino Médio, licenciatura e pós-graduação latu sensu ${ }^{9}$.

O Campus está inserido no Marajó das Águas e Florestas, historicamente conhecido como Estreitos de Breves, formado por diversas ilhas separadas por igarapés, furos, canais e estreitos por onde passam as águas do rio Amazonas e que, ao contornarem o sul do território de Marajó, acabam se unindo às águas do rio Tocantins. Embora com imensas belezas naturais, a mesorregião do Marajó congrega municípios com sofríveis Índices de Desenvolvimento Humano (IDH $)^{10}$, ampliando ainda mais a necessidade e o compromisso institucional em ofertar cursos de acordo com o arranjo produtivo local e integrado ao mundo do trabalho, a fim de contribuir com um novo modelo de desenvolvimento, no caso, sustentável, fundamentado na realidade socioambiental do Marajó.

Relacionado ao projeto do IFPA de educação profissional e tecnológica como constitutiva de sua missão institucional, o Plano de Desenvolvimento Territorial Sustentável do Arquipélago do Marajó, integrado ao Plano Amazônia Sustentável (PAS), planejado a partir de 2007, em relação à educação destaca a “importância de se garantir a efetivação de uma educação voltada para a realidade marajoara com perspectivas de inserção social e desenvolvimento local" (BRASIL, 2007, p 91). Desta forma, observamos que as iniciativas do IFPA Campus Breves estão em consonância com este objetivo, através de cursos, como o de Agropecuária, voltados para as necessidades da comunidade marajoara.

\section{PERCURSO METODOLÓGICO}

A trajetória de construção empírica deste trabalho desenvolveu-se em duas etapas metodológicas que não necessariamente ocorrem em tempos diferentes, mas que são

\footnotetext{
${ }^{9}$ Informações fornecidas pela Secretaria Acadêmica do IFPA Campus Breves em agosto de 2019.

10 Índice de Desenvolvimento Humano Municipal Brasileiro. Brasília: PNUD, Ipea, FJP, 2013, 98p. Disponível em: http://www.atlasbrasil.org.br/2013/data/rawData/publicacao_atlas_municipal_pt.pdf. Acesso em: 14 jul. 2018.
} 
- INOVAÇÃO

complementares, são elas: (1) a metodologia de implementação da oficina; (2) a metodologia para coleta e análise dos dados.

Na primeira etapa (1), que se refere à construção metodológica e aplicação da oficina, foram desenvolvidos o conteúdo programático, a ementa e os argumentos, referentes à área temática central - educomunicação e fotografia -, utilizados para apresentar a teoria e proporcionar um momento de prática para os discentes do curso técnico em Agropecuária e, assim, poderem exercitar os conhecimentos adquiridos. $\mathrm{O}$ conteúdo foi formatado para quatro horas/aula, o equivalente a um turno de aula. A participação ficou restrita aos estudantes do referido curso, dada a problemática identificada especificamente neste grupo.

O conteúdo da oficina foi organizado em um plano de aula contendo os seguintes tópicos: a) a importância da imagem na sociedade atual; b) conceito e história da fotografia; c) fotojornalismo, teoria e técnicas de fotografia; d) atividade prática, Análise crítica e estética; e) avaliação e considerações finais.

Foi utilizado, além do espaço de sala de aula, dois projetores. No primeiro, foi exibida a apresentação principal da oficina. No segundo, através do Chromecast $2^{\circledR}$ (Google Inc., EUA, 2018), equipamento que espelha a tela do celular, mostramos os recursos, configurações e disposições da imagem a ser capturada diretamente do celular do ministrante. A oficina contou ainda com a presença de um professor auxiliar, que contribuiu com intervenções e no acompanhamento dos participantes durante a prática, realizada na área aberta das dependências do IFPA Campus Breves.

A segunda etapa (2) consistiu na coleta, sistematização dos dados e análise teórica do material utilizado como corpus neste trabalho. Esta etapa foi subdividida em dois âmbitos procedimentais: a) coleta e b) e análise.

No primeiro âmbito (a), referente à coleta de dados, utilizou-se a aplicação de questionários que buscavam estabelecer um perfil dos participantes da oficina, assim como o nível de envolvimento com o campo fotográfico. Os questionários, contendo 26 perguntas estruturadas, foram aplicados no ato de entrega dos certificados, e obteve $100 \%$ de retorno dos participantes.

Para a (b) análise, tabulamos os dados coletados nos questionários no programa Excel. As respostas foram estruturadas a partir de tabelas dinâmicas. Questões que apresentavam informações de alta relevância para este trabalho foram cruzadas para se obter o melhor entendimento dos dados. Além do questionário, as experiências e percepções obtidas durante a realização da oficina foram captadas por meio da observação participante, uma técnica em que as informações da realidade são obtidas a partir da interação do pesquisador junto aos sujeitos 
- INOVAÇão

que integram seu objeto de estudo (OLIVEIRA, 2010). Os facilitadores observaram elementos que pudessem evidenciar o envolvimento subjetivo dos participantes com os conhecimentos compartilhados na oficina. Essas informações, dão suporte para a análise aqui desenvolvida.

\section{RESULTADOS E ANÁLISES - PERFIL DOS PARTICIPANTES}

A maioria dos estudantes que participou da oficina de fotografia era do sexo masculino (59\%), na faixa etária de 21 a 25 anos de idade e solteira (91\%). Apenas 13,6\% se consideram negro, branco ou preto; os demais $(86,4 \%)$ se autodenominam como pardos, um termo muito criticado pelas minorias que discutem sobre raça e cor, mas ainda presente entres os dados do Instituto Brasileiro de Geografia e Estatística (IBGE).

O IFPA Campus Breves tem como área de abrangência o correspondente a nove municípios (Afuá, Anajás, Bagre, Breves, Chaves, Curralinho, Gurupá, Melgaço e Portel). No entanto, observou-se uma predominância no público de origem da cidade sede, 50\% proveniente de Breves, seguida pelas duas cidades mais próximas, Curralinho e Portel (13,6\% cada), demonstrando a dificuldade da instituição de envolver estudantes de municípios mais distantes. Para realizar o curso é necessário que o estudante estabeleça residência em Breves, pois as aulas ocorrem em período integral (manhã e tarde). Desta forma, é compreensível o índice de alunos que não trabalham, o equivalente a $86 \%$. A renda familiar informada não passou de dois salários mínimos entre os participantes; 64\% contavam com um a dois salários mínimos e $36 \%$ com menos de um. Uma fonte de recurso que contribui para a permanência deles em sala de aula é o recebimento de Auxílios Estudantis, concedidos pela Instituição a partir do perfil socioeconômico; $86 \%$ recebem o valor que complementa a renda familiar.

\subsection{O conhecimento sobre fotografia}

Uma das premissas para os estudantes participarem da oficina era levar um celular com câmera fotográfica, equipamento necessário para exercitar a aplicação das teorias na atividade prática, simulando a captura das imagens que realizam em campo. Porém, não possuir um smartphone não era um impedimento para os interessados. Somente um deles não possuía o aparelho.

A principal hipótese elaborada ao nos depararmos com a dificuldade de realizar registros fotográficas foi o desconhecimento sobre noções básicas de fotografia e a falta de domínio 
sobre os recursos disponíveis no próprio celular. Dos participantes, $64 \%$ assumiram que não conheciam ou sabiam usar todos os recursos da câmera fotográfica do celular e, desses, $83 \%$ estavam tendo o primeiro contato com os conhecimentos básicos. Isso foi perceptível ao serem levados a experimentar o uso dos recursos do celular para aplicar as técnicas de fotografia.

A descoberta de possibilidades de uso da câmera fotográfica era recebida com surpresa, por desconhecerem o potencial dos equipamentos que tinham consigo, mesmo sendo aparelhos de entrada no mercado; o valor dos celulares não ultrapassava a margem dos $\mathrm{R} \$ 1$ mil, mas com câmeras quem iam de 5 a mais de 12 megapixels, em sua maioria.

No momento em que iniciamos a apresentação do conteúdo, percebemos o interesse dos participantes em descobrir formas de melhorarem suas imagens fotografadas. E havia um motivo para isso: o destino das fotografias feitas pelo celular. Para $73 \%$ dos estudantes, os registros são feitos com a intenção de publicá-los nas mídias sociais, os trabalhos acadêmicos aparecem em segundo lugar, com 50\%.

As noções básicas de fotografia apresentadas poderiam ser facilmente encontradas em sites especializados ou em blogs de profissionais e de amantes da arte de fotografar. Partindo da ideia que poderiam tomar a iniciativa de buscar esses conhecimentos na internet, uma vez que é comum aos jovens o contato com conteúdos autoexplicativos no mais variado leque de interesses, perguntamos o que mais costumavam fazer quando estavam conectados. Nesse ponto, é interessante identificar como eles caracterizam de forma diferente o acesso à internet de acordo com o equipamento utilizado, e essa percepção foi despertada por uma contradição que apresentaram.

A maioria dos participantes (59\%) informou que acessa a internet para estudar e pesquisar assuntos referentes a trabalhos acadêmicos e apenas $18 \%$ confirmou usar a rede para acessar mídias sociais. Ao compararmos esse dado ao destino das imagens (73\% são postadas em mídias sociais), notamos que há uma discordância quando essa maioria não considera o período em que estão acessando as mídias sociais como tempo conectado. Para eles, pelo que se percebe, o acesso à internet ocorre quando estão de frente para um computador e, ao utilizar o celular, parecem ignorar a possibilidade de navegar pelos mesmos conteúdos, não se limitando ao uso de aplicativos e mídias sociais.

Esse interesse em utilizar as imagens para as mídias sociais foi reforçado pelo comportamento que apresentaram durante a oficina, demonstrando maior participação nos conteúdos referentes à prática de fotografar, ao esclarecer dúvidas e expor opiniões, do que nos conhecimentos teóricos que exploravam o histórico e os princípios mais abstratos. No decorrer da exposição desses últimos conteúdos citados, era comum eles verificarem, de forma discreta, 
notificações de mídias sociais, recebimento de mensagens ou, simplesmente desbloquearem e em seguida retornarem o celular para o modo em espera. A atenção era retomada quando o assunto passava a se caracterizar como uma dica.

\subsection{A importância de obter as noções básicas de fotografia}

Para 91\% dos participantes, as noções básicas de fotografia adquiridas na oficina melhoraram a qualidade de imagens capturadas pela câmera do celular, um dado significativo quando consideramos que o questionário foi aplicado depois de um pouco mais de 60 dias após a realização da oficina.

Com o maior foco do destino das imagens para as mídias sociais, $72 \%$ dos estudantes afirmaram que perceberam um aumento no número de curtidas e comentários em fotos publicadas. Uma questão que buscou confirmar o aumento da qualidade das imagens capturadas por meio da percepção de terceiros, mesmo sabendo que existem outros diversos fatores que influenciam o volume de interação nessas mídias.

A partir do conhecimento adquirido, seria natural que os participantes dedicassem um pouco mais de tempo para fotografar com o intuito de produzirem melhores fotografias. Para $82 \%$ dos estudantes, esse foi um comportamento adotado, visto a necessidade de ajustes e adequação das configurações da câmera do celular ao contexto e ambiente do objeto da fotografia.

Na vida acadêmica, os estudantes foram unânimes (100\%) ao confirmar que acreditam que os novos conhecimentos adquiridos contribuem à produção de melhores imagens para retratar a realidade marajoara nos trabalhos e pesquisas desenvolvidas no curso. Uma percepção que evidencia, mesmo sem a possibilidade de aplicar de forma imediata algum método comprobatório, que o objetivo principal da oficina foi alcançado e que o acesso a noções básicas contribuirá diretamente para expressão dos participantes sobre a compreensão e percepção que têm a respeito da realidade que vivenciam em suas comunidades.

\section{CONSIDERAÇÕES FINAIS}

A comparação entre os dados sobre o desconhecimento que os estudantes tinham a respeito de noções básicas de fotografia $(55 \%)$ e dos recursos da câmera fotográfica do celular (64\%) com a percepção de melhoria na captura de imagens (91\%) e do impacto positivo que exercem nos trabalhos acadêmicos (100\%) demonstra que a aplicação de práticas e abordagens 
da Educomunicação apresentam significativos resultados para o processo de ensino na Educação Profissional e Tecnológica.

O perfil e a realidade socioeconômica dos estudantes, juntamente com as limitações a que estão sujeitos, seja de acesso a recursos, seja pela formação em um ensino básico deficitário, pode justificar o desconhecimento do uso de recursos da câmera fotográfica do próprio celular, mas, ao mesmo tempo, aponta para uma característica de uma geração que, imersa às inovações tecnológicas, despreocupa-se ou não está disposta de forma autônoma a adquirir conhecimentos da base do saber. É nesse contexto que a Educomunicação atua como um campo de mediação que permite a ligação desses dois pontos: aproveita a pré-disposição e facilidade que o educando tem em lidar com as tecnologias e potencializa os processos de ensino-aprendizagem a partir da interação com tais recursos.

A familiaridade com que os jovens estudantes utilizam recursos tecnológicos, seja a manipulação de equipamentos ou a facilidade em encontrar informações úteis na internet, não garante que eles dominem o conhecimento teórico sobre o funcionamento e a potencialidade disponibilizados por eles. A Educomunicação, no seu papel mediador entre a tecnologia e os processos educativos, contribui para que essa lacuna no saber e entender os recursos da tecnologia da informação e comunicação seja preenchida, possibilitando o alcance de melhores resultados na busca de uma educação cidadã e emancipatória.

\section{Referências}

ALMEIDA, Lígia Beatriz Carvalho de. Projetos de intervenção em educomunicação. Campina Grande-PB, 2016. Disponível em: https://edisciplinas.usp.br/pluginfile.php/4615056/mod_resource/content/1/Projetos de Intervenção.pdf . Acesso em 23 set. 2019.

ARAUJO, Ronaldo; FRIGOTTO, Gaudêncio. Práticas pedagógicas e ensino integrado. Revista Educação em Questão, Natal, v. 52, n. 38, p. 61-80, mai/ago. 2015. Disponível em: https://periodicos.ufrn.br/educacaoemquestao/article/view/7956/5723. Acesso em 23 set. 2019.

BRASIL. Governo Federal. Grupo Executivo Interministerial. Plano de Desenvolvimento Territorial Sustentável para o Arquipélago do Marajó: resumo executivo da versão preliminar para discussão nas consultas públicas / Governo Federal, Grupo Executivo Interministerial. - Brasília: Editora do Ministério da Saúde, 2007.

INSTITUTO FEDERAL DO PARÁ. Projeto Pedagógico do Curso Técnico em Agropecuária Subsequente ao Ensino Médio. Campus Breves-PA, 2016. Disponível em: http://breves.ifpa.edu.br/documentos/audin/1265-tecnico-em-agropecuaria-1/file . Acesso em 23 set. 2019. 


\section{INOVAÇÃO}

CORREA, Avani Maria de Campos. Educomunicação: Aspectos Históricos e Perspectiva no Brasil. In: SILVA, Diva (Org.). Educomunicação: reflexões e práticas educativas. $1^{\mathrm{a}}$ Ed. Eletrônica. Uberlândia: Navegando, 2017. Disponível em: https://issuu.com/navegandopublicacoes/docs/combinepdf__1_-min_b5bd635e73fa88 . Acesso em 23 set. 2019.

KOFFERMANN, Marcia. Como sistematizar um Projeto Educomunicacional? $1^{\text {a }}$ Ed. Brasília: Edebê Brasil, 2018, 16p.

MAUAD, Ana Maria. Através da Imagem: fotografia e história-interfaces. Tempo, Rio de Janeiro, v. 1, n. 2, p. 73-98, dez. 1996. Disponível em:

http://www.historia.uff.br/tempo/artigos_dossie/artg2-4.pdf . Acesso em 23 set. 2019.

MARTÍN-BARBERO, Jesús. Dos meios às mediações: comunicação, cultura e hegemonia. Rio de Janeiro: Editora UFRJ, 1997.

MARTÍN-BARBERO, J.; BARCELOS, C. Comunicação e mediações culturais. Intercom Revista Brasileira de Ciências da Comunicação, Rio de Janeiro, v. 23, n. 1, p. 151-163, 2000. Disponível em: http://www.portcom.intercom.org.br/revistas/index.php/revistainter com/article/view/2010/1788. Acesso em 23 set. 2019.

OROZCO GÓMEZ, Guilherme. Educação: recepção midiática, aprendizagens e cidadania. São Paulo: Paulinas, 2014.

OLIVEIRA, Maria Marly de. Como fazer pesquisa qualitativa. 3 ed. Petrópolis, RJ: Vozes, 2010.

OLIVEIRA, Marta Olivia Rovedder de; UBAL, Danine Chaiane Pereira das Neves; CORSO, Kathiane Benedi. Meu smartphone, uma extensão de mim: self estendido e os paradoxos tecnológicos. In: Anais do XVII Seminário em Administração. São Paulo, SP, Brasil, 2014. Disponível em: http://sistema.semead.com.br/17semead/resultado/trabalhosPDF/671.pdf . Acesso em 23 set. 2019.

PACHECO, Agenor Sarraf. Os estudos culturais em outras margens: identidades afroindígenas em "zonas de contato" amazônicas. Fênix Revista de História e Estudos Culturais, Uberlândia, n. 3, v. 9, p. 1-19, set./dez. 2012. Disponível em: http://www.revistafenix.pro.br/downloadpdf.php?file=PDF30/ARTIGO_1_SECAO_LIVRE_AGENOR_SARRAF_PACHECO_FENI X_SET_OUT_NOV_DEZ_2012.pdf . Acesso em 23 set. 2019.

PERUZZO, Cicilia M. Krohling. Direito à comunicação comunitária, participação popular e cidadania. Lumina, Juiz de Fora, v. 1, n. 1, p. 1-29, jun. 2007. Disponível em: https://periodicos.ufjf.br/index.php/lumina/article/view/20989 . Acesso em 23 set. 2019.

SHULMAN, Lee S. Conhecimento e ensino: fundamentos para a nova reforma. Cadernos Cenpec, São Paulo, v. 4, n. 2, p. 196-229, dez. 2014. Disponível em: http:// cadernos.cenpec.org.br/cadernos/index.php/cadernos/article/view/293/297. Acesso em 23 set. 2019. 


\section{- inOVAção}

SOARES, Ismar de Oliveira. Educomunicação: o conceito, o profissional, a aplicação: contribuições para a reforma do Ensino Médio. São Paulo: Paulinas, 2011.

SOARES, Ismar de Oliveira. Educomunicação: um campo de mediações. Comunicação \& Educação, São Paulo, n. 20, p. 12-24, set/dez. 2000. Disponível em:

http://www.journals.usp.br/comueduc/article/view/36934/39656 . Acesso em 23 set. 2019. 


\section{REFERENCIAS}

ARAÚJO, V. M. R. H. A organização espacial da informação científica e tecnológica no Brasil. Ciência da Informação, Brasília, v. 14, n. 1, p. 17-24, jan./jun. 1985.

BRASIL. Ministério da Ciência, Tecnologia e Inovação (MCTI). Indicadores Nacionais de CT\&I: apresentação. Brasília, 2012a. Disponível em: <http://www.mct. gov.br/index.php/content/view/2043.html>. Acesso em: 20 jul. 2017.

BRASIL. Ministério da Ciência, Tecnologia e Inovação (MCTI). Indicadores Nacionais de CT\&I: histórico. Brasília, 2012b. Disponível em: <http://www.mct.gov. br/index.php/content/view/2044/Historico.html>. Acesso em: 20 jul. 2017.

CAVAlCANTE, L. R. Políticas de Ciência, Tecnologia e Inovação no Brasil: uma análise com base nos indicadores agregados. Rio de Janeiro: Secretaria deAssuntos Estratégicos da Presidência da República, 2009. Disponível em: <http:// www.ipea.gov.br/portal/images/stories/PDFs/TDs/td_1458.pdf>. Acessoem: 31 jul. 2017.

COLE, S.; COLE, J. R. Visibility and the structural bases of awareness of scientific research. American Sociological Review, [S. 1.], v. 33, n. 3, p. 397-413, 1968.

CONSELHO NACIONAL DE DESENVOLVIMENTO CIENTÍFICO E TECNOLÓGICO (CNPq). Programas. 2017. Disponível em: <http://cnpq.br/\#void〉. Acesso em: 13 jul. 2017.

COORDENAÇÃO DE APERFEIÇOAMENTO DE PESSOAL DE NÍVEL SUPERIOR(Capes).

Portal de Periódicos. 2017a.Disponível em: <http://www.periodicos. capes.gov.br>. Acesso em: 26 jul. 2017a.

COORDENAÇÃO DE APERFEIÇOAMENTO DE PESSOAL DE NÍVEL SUPERIOR(Capes). Prêmio Capes Teses. 2017b.Disponível em: <http://www.capes.gov.br/ premiocapesdetese>. Acesso em: 26 jul. 2017b.

COORDENAÇÃO DE APERFEIÇOAMENTO DE PESSOAL DE NÍVEL SUPERIOR(Capes). Sobre a avaliação. 2017c.Disponível em: <http://capes.gov.br/avaliacao/sobre-a-avaliacao>. Acesso em: 27 jul. $2017 \mathrm{c}$.

DIAS, R. B. O que é a política científica e tecnológica. Sociologias, Porto Alegre, v. 13, n. 28, p. 316-344, set./dez. 2011. 